\title{
OPERATIVE ESTIMATION OF SEAWORTHINESS OF SHIP BY IMITATION DESIGN OF HIS LOADING
}

\author{
ОПЕРАТИВНАЯ ОЦЕНКА МОРЕХОДНОСТИ СУДНА \\ ИМИТАЦИОННЫМ МОДЕЛИРОВАНИЕМ ЕГО ЗАГРУЗКИ
}

\author{
A.V. Gaychenya, senior lecturer \\ А.В. Гайченя, к.т.н., стариий преподаватель \\ National University «Odessa Maritime Academy», Ukraine \\ Национальный университет «Одесская морская академия», Украина
}

\begin{abstract}
The method of the use of imitation design is offered for placing of cargo on to the holds of и ballast on to the tanks taking into account the operative control of parameters of nautical safety of ship, which provides the safe loading of ship.

The program with the module of interactive by introduction of parties of cargo was used for this purpose, accepted to transportation, and by the module of distributing cargo on to the holds of ship of and ballast on to the tanks. This software product was used for forming of previous cargo plan of ship taking into account the requirements of nautical safety. A case is considered, when to the loading 12 parties of cargo are accepted.

At placed to the cargo by the program express hatches information about parameters of ship. In the article the described procedure of the imitation placing of parties cargo on to the holds of ship, thus the parameters of landing of ship, parameters and general longitudinal durability change taking into account the accepted cargo.

For the control of general longitudinal durability at the design of loading of ship hatch graphics cutting forces and curving moments which are compared to maximum - the possible graphs, on the basis of what the conclusion of admission of loading is conducted on longitudinal durability. If current graphics cutting forces and curving moments are in possible scopes, the design of loading proceeds. Differently it follows to change placing or weight of the last party of the accepted cargo or conduct the change of present ballast by the redistribution of his amount on to the ballast tanks.

Conducting of taking ballast of ship for the redistribution of amount of ballast on to the tanks an imitation is foreseen by the loading routine of ship. With the help of procedure of taking ballast it is needed to choose on the computer chart of ship a tank for ballast operation, and then declare the type of operation: partial or complete reception of ballast, or partial or complete drainage to the tank.

As a result of imitation of taking ballast of ship, displacement of ships, static change moment in relation to ship planes, that conduces to the change of parameters of nautical safety of ship. Therefore, at the design of taking ballast of ship current
\end{abstract}


information hatches on to the parameters of landing of ship and general longitudinal durability.

By the resulted method of design of loading of ship possibility of choice of optimum previous cargo plan of ship appears by the imitation program.

Keywords: nautical safety of ship, loading of ship, imitation design.

\section{РЕФЕРАТ}

Запропоновано спосіб використання імітаційного моделювання для розміщення вантажу по трюмам и баласту по танкам 3 урахуванням оперативного контролю параметрів морехідної безпеки судна, який забезпечує безпечне завантаження судна.

Для цього була використана програма з модулем інтерактивного введення партій вантажу, прийнятих до перевезення, та модулем розподілу вантажу по трюмам судна и баласту по танкам. Цей програмний продукт був використаний для формування попереднього вантажного плану судна 3 урахуванням вимог морехідної безпеки. Розглянуто випадок, коли до завантаження прийнято 12 партій вантажу.

При розміщені вантажу програмою виводиться експрес інформація про остійність судна. В статті описана процедура імітаційного розміщення партій вантажу по трюмам судна, причому параметри посадки судна, остійності i загальної подовжньої міцності змінюються з урахуванням прийнятого вантажу.

Для контролю загальної подовжньої міцності при моделюванні завантаження судна виводяться графічні епюри перерізуючих сил та вигинаючих моментів, які порівнюються з гранично - допустимими графіками, на основі чого проводиться висновок допустимості завантаження по подовжньої міцності. Якщо поточні епюри перерізуючих сил та вигинаючих моментів знаходяться в допустимих межах, то продовжується моделювання завантаження. Інакше слід змінити розміщення або вагу останньої партії прийнятого вантажу або провести зміну наявного баласту шляхом перерозподілу його кількості по баластним танкам.

Проведення баластування судна для перерозподілу кількості баласту по танкам передбачено імітаційної програмою завантаження судна. За допомогою процедури баластування потрібно вибрати на комп'ютерній схемі судна танк для баластної операції, а потім заявити тип операції: частковий чи повний прийом баласту, або часткове чи повне осушення танку.

В результаті імітації баластування судна змінюються водовантажність судна, статичні моменті відносно суднових площин, що веде до зміни параметрів морехідної безпеки судна. Тому при моделюванні баластування судна виводиться поточна інформація по параметрам посадки судна, остійності і загальної подовжньої міцності.

За допомогою приведеного способу моделювання завантаження судна імітаційною програмою з'являється можливість вибору оптимального попереднього вантажного плану судна. 
Ключові слова: морехідна безпека судна, завантаження судна, імітаційне моделювання.

Постановка проблемы в общем виде и ее связь с важными научными или практическими задачами

Загрузка морских судов в значительной мере определяет их мореходную безопасность. Поэтому при составлении грузового плана судна целесообразно производить оперативную оценку его мореходной безопасности, располагая перечнем предлагаемых к перевозке грузов. Очевидно, в качестве технического средства, с помощью которого возможна оперативная оценка мореходной безопасности, можно использовать компьютерную программу, чему и посвящена данная работа.

Анализ последних достижений и публикаций, в которых начато решение данной проблемы и выделение нерешенных ранее частей общей проблемы

Вопросы формирования оптимальной загрузки навалочных судов рассмотрены в работе [1]. Метод оптимизации загрузки судна тарно-штучными грузами предлагается в работе [2].

В работах [3-6] рассмотрены вопросы разработки метода оперативной оценки критериев мореходности судна.

\section{Формулировка целей статьи}

Целью данной статьи является анализ возможности разработки способа оперативного мониторинга состояния мореходной безопасности судна в процессе формирования его грузового плана.

\section{Изложение основного материала исследования с обоснованием полученных научных результатов}

Основой разработки компьютерной программы оперативной оценки мореходной безопасности судна послужили работы [3-6], с помощью которых была сгенерирована программа определения параметров посадки, остойчивости и продольной прочности восьми трюмного балкера. Программа была дополнена модулем интерактивного ввода партий груза, принятых к перевозке и модулем распределения груза по трюмам судна и балласта по танкам. Полученный программный продукт явился инструментом формирования предварительного грузового плана судна с учетом требований мореходной безопасности. На рис. 1 показан начальный интерфейс программы для случая, когда к перевозке приняты 12 партий груза (всего программой предусмотрен прием до 36 партий). С каждой из партий груза связана управляющая клавиша, на которой помещено условное изображение партии принимаемого груза, общий вес партии и вес ее погруженной на судно части. В начальном состоянии во всех трюмах судна отсутствует груз, а на всех клавишах партий вес принятого груза равен 0 . На нижней левой части экрана выводится информация о посадке судна и общей продольной прочности корпуса, представленной эпюрами перерезывающих сил 
и изгибающих моментов. Выводятся значения осадок судна носом, кормой, средней осадки и дифферента судна. Также указывается общий вес груза,

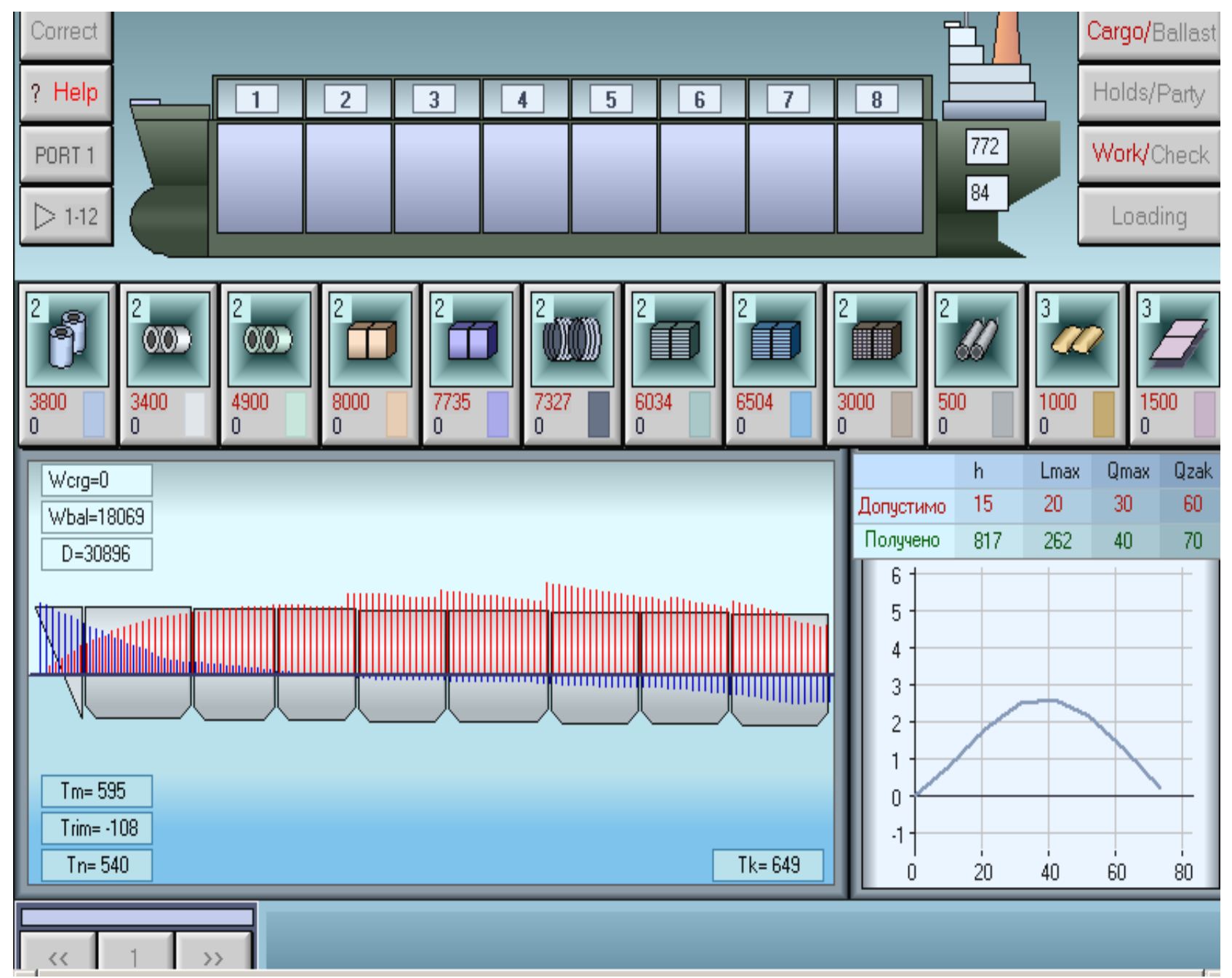

Рис. 1. Начальный интерфейс программы

принятого на судно $\left(\mathrm{W}_{\mathrm{crg}}=0\right)$, вес балласта (в начальном состоянии судном принят балласт полностью $\left.\mathrm{W}_{\mathrm{bal}}=18069 \mathrm{~T}\right)$ и водоизмещение $\mathrm{D}$. B правой нижней части экрана выводится экспресс информация об остойчивости судна. Для размещения партий груза по трюмам судна следует выбрать партию груза, "кликнув" по соответствующей клавише, как показано на рис. 2 выбрана четвертая клавиша, а затем указывается трюм, в который планируется загрузка выбранной партии (в примере трюм 5). После этого с помощью клавиш в нижней левой части экрана выбирается часть загружаемой партии (в примере вся партия "1"), и на экране с учетом удельного погрузочного объема отображается загруженный трюм 5 (рис. 2). С учетом принятого груза изменяются параметры посадки судна, остойчивости и общей продольной прочности. 


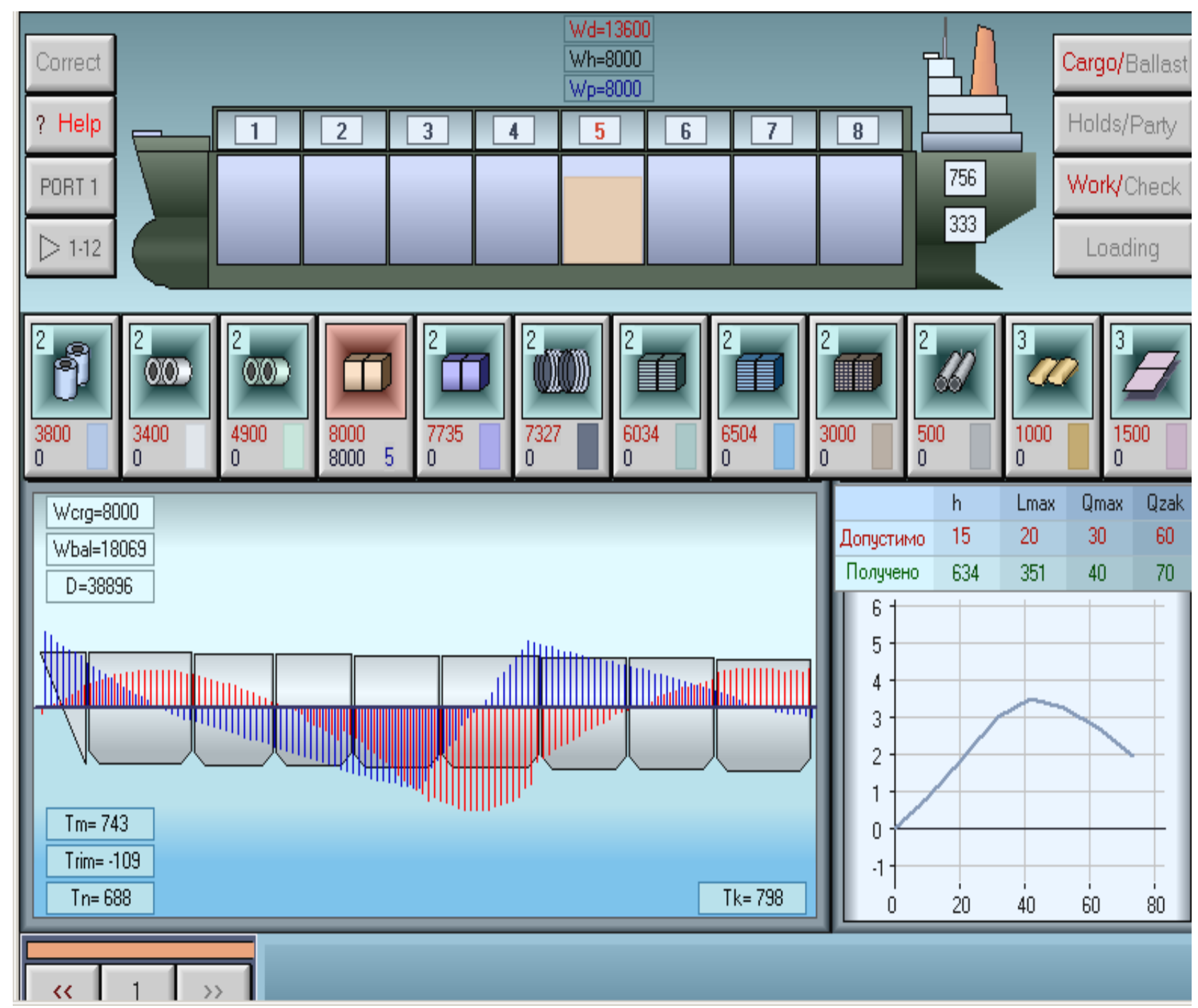

Рис. 2. Результать загрузки четвертой партии в трюм 5

Затем, как показано на рис. 3, в трюм 2 принята партия груза 5, а в трюм 7 загружены три партии груза 1, 9 и 12, что нашло свое отображение на схеме грузовых помещений судна и выводе информации о параметрах мореходной безопасности, которые находятся в допустимых пределах. Правда, изгибающие моменты близки к пределу в кормовой оконечности судна. Поэтому, как показано на рис. 4, произведено изменение распределения балласта, для чего клавишей "Cargo/Ballast" выбран режим балластировки и "кликанием" носового подвесного балластного танка производится его осушение. Из рис. 4 следует, что при этом угроза со стороны изгибающих моментов ликвидирована. По указанной процедуре производится размещение груза по трюмам судна, производя текущий контроль параметров мореходной безопасности судна, обеспечивая их допустимые значения. 


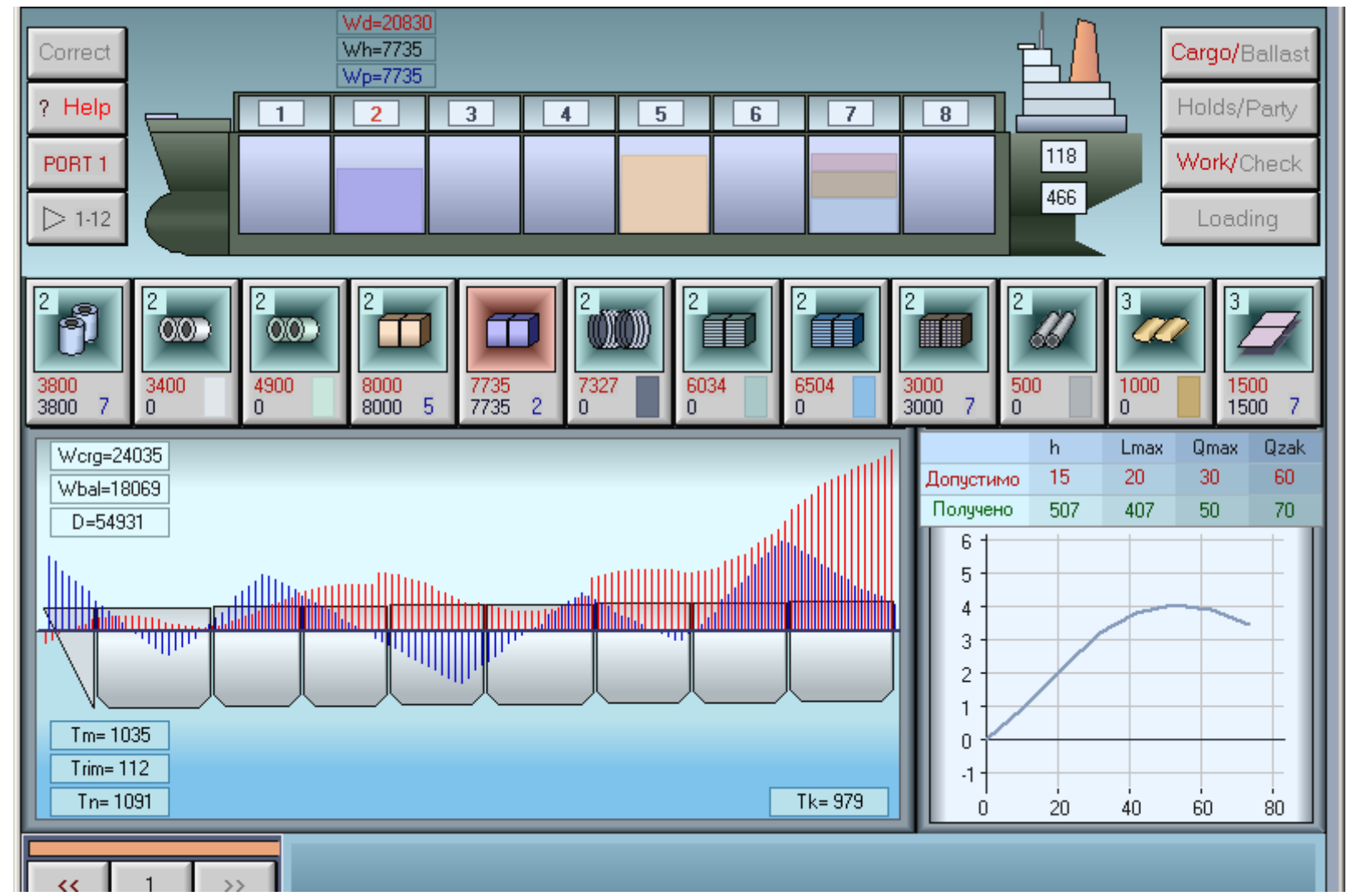

Рис. 3. Загрузка трюмов 2 и 7

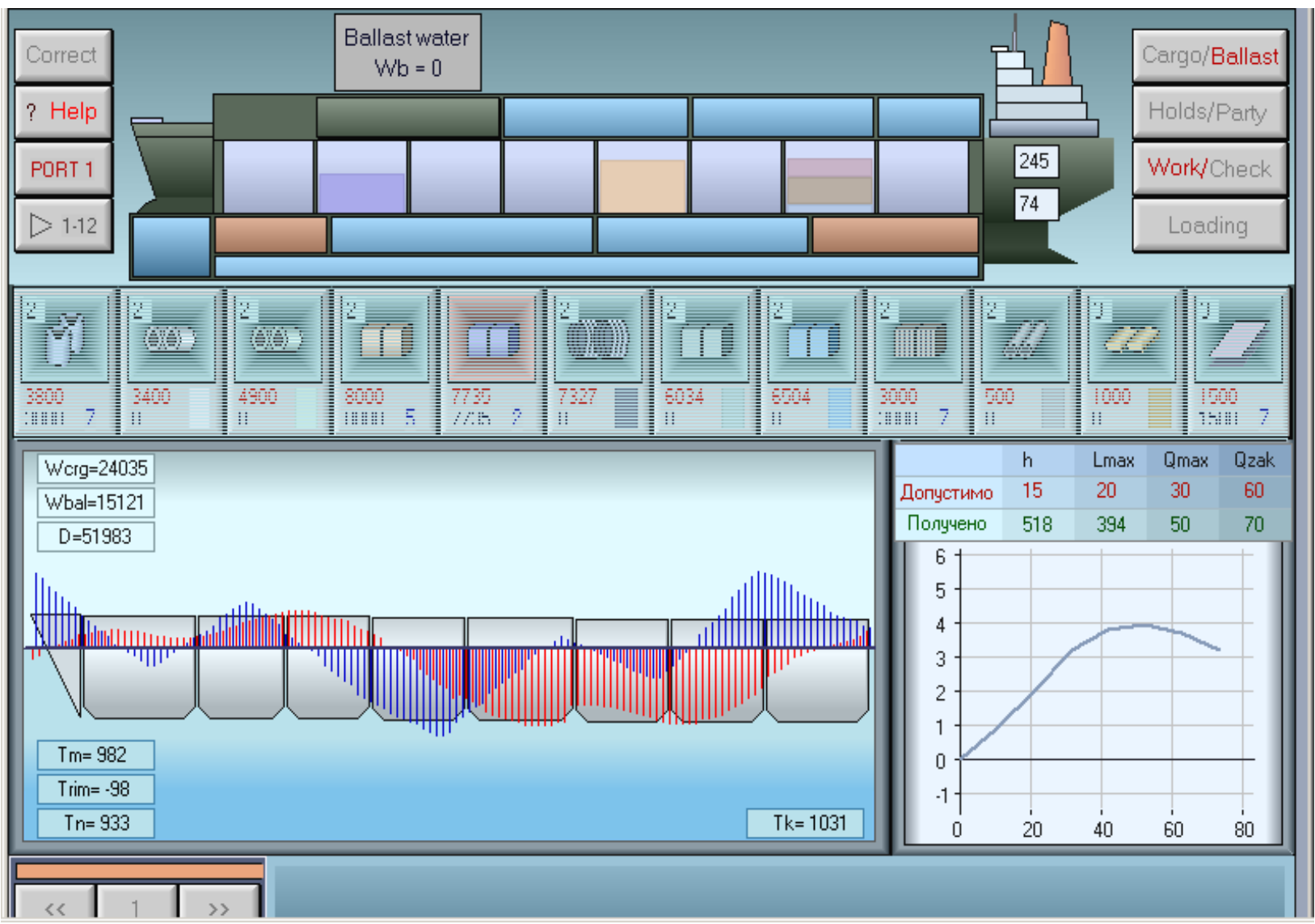

Рис. 4. Осушение балластного танка 
На рис. 5 показано окончательное размещение груза по трюмам. В результате балластом заполнен только ахтерпик, а груз размещен по всем трюмам. К перевозке не принята только вторая партия груза из-за полного использования грузоподъемности судна.

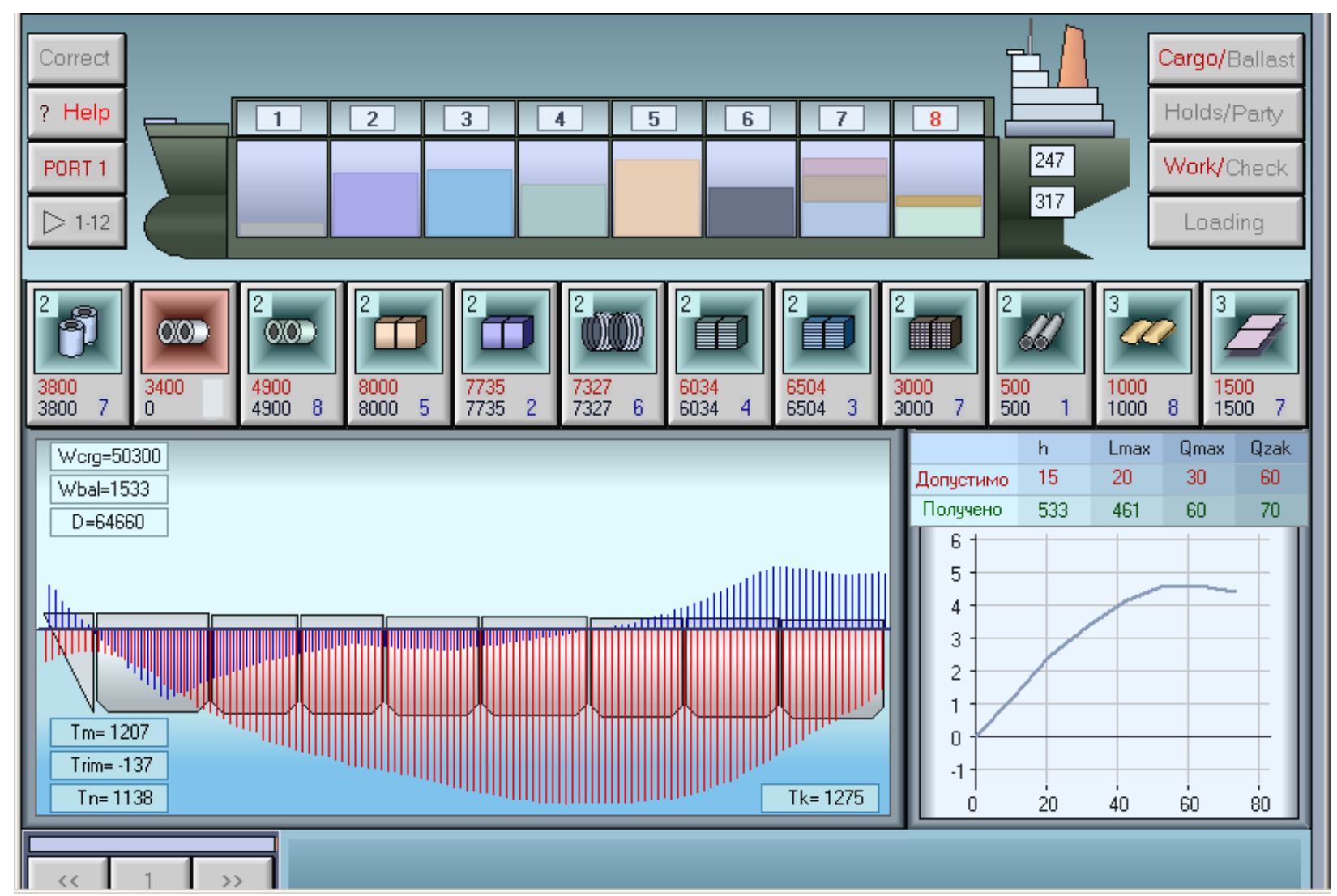

Рис. 5. Окончательное размещение груза

Выводы и перспектива дальнейшей работы по данному направлению

Таким образом, предложен способ размещения груза по трюмам и балласта по танкам с учетом оперативного контроля параметров мореходной безопасности судна, который обеспечивает безопасную загрузку судна. В дальнейшем предлагается исследовать возможность использования предлагаемого способа для оптимальной загрузки судна.

\section{ЛИТЕРАТУРА}

1. Цымбал Н.Н. Формирование оптимизационной задачи проведения грузовых операций навалочных судов./ Цымбал Н.Н., Васьков Ю.Ю. // Судовождение. - 2004. - № 7. - С. 3 - 10.

2. Чепок А.О. Оптимизация загрузки судна тарно-штучными грузами в автоматизированных системах. / Чепок А.О. // Проблеми техники: Научнопроизводственный журнал / ОНМУ, ХНУ - 2013. - № 4. - Одесса: Одесский национальный морской университет, 2013. - С. 44-51.

3. Николаева Л.Л. Разработка метода оперативной оценки критериев 
мореходности судна. / Николаева Л.Л., Гайченя А.В., Соколов М.Ю.// Судовождение: Сб. научн. трудов. / ОНМА, Вып. 16. - Одесса: ИздатИнформ, 2009. - С.132-136.

4. Николаева Л.Л. Способ формализации формы судовых грузовых помещений нестандартного типа / Николаева Л.Л., Гайченя А.В. // Автоматизация судовых технических средств. - 2010. - № 16. - С. 71-82.

5. Гайченя А.В. Ввод в базу данных характеристик судна / Гайченя А.В. // Судовождение: Сб. научн. трудов. / ОНМА, Вып. 18. - Одесса: ИздатИнформ, 2010. - С. 64-67.

6. Гайченя А.В. Ввод информации о танках в базу данных судна / Гайченя А.В. // Судовождение: Сб. научн. трудов. / ОНМА, Вып. 19. - Одесса: ИздатИнформ, 2011. - С. 71-75. 